\title{
$\beta$-Carotene: Radical Reactions and Cancer Associations-Leading Down a Rabbit Hole?
}

\section{Homer S Black ${ }^{1^{*}}$, Ruth Edge ${ }^{2}$ and TG Truscott ${ }^{3}$}

${ }^{1}$ Department of Dermatology, Baylor College of Medicine, Houston, USA

${ }^{2}$ Dalton Cumbrian Facility, Westlakes Science and Technology Park, University of Manchester, Cumbria, UK

${ }^{3}$ School of Physical and Geographical Sciences (Chemistry Section), Keele University, Staffordshire, UK

\section{Editorial}

Approximately 600 carotenoids have been identified with about 100 finding their way into foodstuffs consumed by humans [1]. These pigments are widely distributed as naturally occurring constituents of fruits and vegetables. They are often added to human foodstuffs in order to achieve acceptable food coloration as they strongly absorb light in the region of 400-500 $\mathrm{nm}$ and are colored red, orange, and yellow. Chemically these pigments are tetraterpenoids consisting of eight isoprenoid residues. Carotenoids serve in a protective role to photosensitization by endogenous photosensitizers such as the porphyrin-containing photosynthetic pigments and in the human genetic disorder Erythropoietic protoporphyria. $\beta$-carotene is an important micronutrient for human health as it is a non-toxic precursor for the synthesis of vitamin A. Its role in affecting a reduction in cancer incidence is in question.

$\beta$-Carotene was shown to be an efficient quencher of singlet oxygen (Eq. 1) in 1968 [2]. The reverse reaction was not observed. The ${ }^{3} \mathrm{Car}$ does react with oxygen but by enhanced intersystem crossing and not via energy transfer and thus, no singlet oxygen is produced [3]. It was generally thought that the rate of singlet oxygen quenching paralleled its protective action [4].

$$
\mathrm{O}_{2}\left({ }^{1} \Delta_{2}\right)+\mathrm{Car} \rightarrow{ }^{3} \mathrm{Car}+\mathrm{O}_{2}
$$

However, Mathews-Roth, et al. [5] found that the protective action of a series of carotenoids didn't necessarily parallel the $\mathbf{O}_{2}\left({ }^{1} \Delta_{2}\right)$ quenching capacity and suggested that carotenoids might interfere with radical reactions initiated in vivo [6]. Subsequently, it was shown that carotenoids could effectively inhibit lipid peroxidation in microsomal membranes by mechanisms not initiated by $\mathbf{O}_{2}\left({ }^{\mathbf{1}} \Delta_{2}\right)$ [7]. Carotenoid antioxidant efficiency was influenced by several factors including the type of radical initiator and the site and rate of radical formation [6].

Critical to an understanding of the biological responses to carotenoids, it was shown that $\beta$-carotene exhibited good radical trapping antioxidant behavior at partial oxygen pressures significantly less than 150 Torr (pressure of $\mathrm{O}_{2}$ in normal air). At higher $\mathrm{O}_{2}$ pressure $\beta$-carotene lost its antioxidant capacity and exhibited autocatalytic, pro-oxidant effects [8]. However, these results were obtained in a nonbiological environment (chlorobenzene solvent) so that the actual oxygen levels at which a switch from anti- to pro-oxidative behavior that was observed in this study may not be relevant to a biological environment. Related to these results, it was found that at very low oxygen concentrations only the carotenoid radical cation (Car $\left.{ }^{-}\right)$was observed (via electron transfer) when reacting with an oxygen-centered radical such as a peroxyl radical (Eq. 2) [9]. The radical cation is observed when reacting with $\mathrm{CCl}_{3}$. but another radical is also observed (as well as the radical cation) in the presence of oxygen, i.e., on reaction with $\mathrm{CCl}_{3} \mathrm{O}_{2}$. Presumably, this second radical is a peroxyl radical adduct.

$$
\mathrm{RO}_{2}{ }^{-}+\mathrm{CAR} \rightarrow \mathrm{RO}_{2}^{-}+\mathrm{Car}^{\cdot+}
$$

More recently a potential mechanism to explain a large oxygen concentration response to cell protection against $\mathrm{OH} \cdot$ by lycopene (Lyc) was proposed [10]. $\beta$-carotene behaves in a similar manner [Boehm, Edge, Truscott, in preparation]. The $\mathrm{OH} \cdot$ was generated via high energy $\gamma$-radiation of aqueous solutions. The mechanism of cell protection did not involve carotenoid radical cations but, instead, the removal of the damaging $\mathrm{OH} \cdot$ radical by the formation of the neutral $\cdot \mathrm{LycOH}$ radical. At higher oxygen concentrations the anti-oxidant effect was totally lost due to the production of reactive peroxyl radicals ( $\left.{ }^{\circ} \mathrm{OOLycOH}\right)$ (Eq. 3 and 4) that are formed in increasing concentrations as the oxygen level increases.

$$
\begin{aligned}
& \mathrm{Lyc}+\mathrm{OH} \cdot \rightarrow \cdot \mathrm{LycOH} \\
& \cdot \mathrm{LycOH}+\mathrm{O}_{2} \leftrightharpoons \cdot \mathrm{OOLycOH}
\end{aligned}
$$

An epidemiological study in 1981 reported that individuals that consumed greater levels of green, leafy vegetables exhibited a lower risk for cancer [11]. Because these foods are rich in $\beta$-carotene and based upon the carotenoids specific capacity to quench singlet oxygen, scavenge oxy-radicals, and terminate free radical reactions, it was suggested that $\beta$-carotene might be responsible for this anticancer potential. This opened a groundswell of interest in $\beta$-carotene as an anti-cancer agent. Indeed, many observational studies, based on dietary carotenoid intake, have shown inverse relationships with cancer incidence. These include lung, colon, breast, and prostate [12].

However, in the face of rather overwhelming epidemiological evidence, clinical trials failed to support such a connection. Greenberg et al [13] reported that "in persons with a previous non-melanoma skin cancer, treatment with beta-carotene does not reduce the occurrence of new skin cancers over a five-year period of treatment and observation". Clinical trials abruptly ended when investigators "found no reduction in the incidence of lung cancer among male smokers after five to eight years of dietary supplementation with $\alpha$-tocopherol or beta-carotene" [14].

Disturbingly, they found that "among the men who received betacarotene, an excess cumulative incidence of lung cancer was observed after 18 months and increased progressively thereafter, resulting in an $18 \%$ difference $(\mathrm{p}=0.01)$ in incidence by the end of the study".

Nor were results from studies of experimental UV-carcinogenesis straightforward. Early studies had shown that $\beta$-carotene supplemented diets were significantly protective to UV-induced carcinogenesis

${ }^{*}$ Corresponding author: Homer S Black, Department of Dermatology, Baylor College of Medicine, Houston, Texas, USA, Tel: 832-741-1052; E-mail: hblack@bcm.edu

Received October 24, 2018; Accepted October 30, 2018; Published November 06, 2018

Citation: Black HS, Edge R, Truscott TG (2018) $\beta$-Carotene: Radical Reactions and Cancer Associations-Leading Down a Rabbit Hole? J Integr Oncol 7: e113. doi: 10.4172/2329-6771.1000e113

Copyright: ( 2018 Black HS, et al. This is an open-access article distributed under the terms of the Creative Commons Attribution License, which permits unrestricted use, distribution, and reproduction in any medium, provided the original author and source are credited. 
$[15,16]$. Later studies failed to find a protective effect of the carotenoid but rather found a significant exacerbation of UV-carcinogenesis, both with respect to tumor latent period and tumor multiplicity [17]. Upon careful examination of the experimental variables of our studies with experimental parameters of the earlier studies, it was found that the earlier studies, in which photo-protection was found, employed "closed-formula" diets where the studies in which exacerbation occurred employed a semi-defined diet. The latter would have no other carotenoids or phytochemicals other than that provided as a supplement, i.e., $\beta$-carotene. When UV-carcinogenesis studies were repeated using both current closed-formula and semi-defined diets, no photo-protection or exacerbation with the closed-formula ration occurred whereas significant exacerbation of carcinogenesis occurred with the semi-defined diet [18].

Based upon relative electron transfer rate constants for interactions between $\beta$-carotene, vitamin $\mathrm{E}$ ( $\alpha$-tocopherol) and vitamin $\mathrm{C}$ (ascorbic acid) [19], a mechanism was proposed by which $\beta$-carotene participates in quenching oxy radicals and interacts to enhance the antioxidant properties of vitamins $\mathrm{E}$ and $\mathrm{C}$ [20]. In the proposed mechanism a-tocopherol first intercepts an oxy radical (Eq. 5), terminating the radical propagating reaction and producing the tocopherol radical cation. This, in turn, would be repaired by $\beta$-carotene to form the carotenoid radical cation (Eq. 6) that, in turn, would be repaired by ascorbic acid (Eq.7). It was theorized that a deficiency in vitamin $\mathrm{C}$ could result in accumulation of the carotenoid radical cation, a highly oxidative species that might participate in the pro-carcinogenic activity.

$$
\begin{aligned}
& \mathrm{RO}_{2}+\mathrm{TOH} \rightarrow \mathrm{TOH}^{++}+\mathrm{ROOH} \\
& \mathrm{TOH}^{++}+\mathrm{Car} \rightarrow \mathrm{TOH}+\mathrm{Car}^{\cdot+} \\
& \mathrm{Car}^{++}+\text {Asch } \rightarrow \mathrm{Car}+\mathrm{Asc}^{++}
\end{aligned}
$$

However, when vitamin $\mathrm{C}$ supplementation was increased 6-fold in the semi-defined diet or eliminated from the diet, there were no significant changes in the level of exacerbation induced with $\beta$-carotene [21]. Nor was there any effect of increasing vitamin $E$ levels 10-fold. Nonetheless, when vitamin E levels were lowered to that found in the closed-formula diet, exacerbation of tumor multiplicity increased nearly 6-fold [22]-confirming an interaction of vitamin $\mathrm{E}$ and $\beta$-carotene. Assuming that vitamin $\mathrm{E}$ and $\beta$-carotene interact to terminate oxy-radical propagation with the formation of the $\beta$-carotene radical cation, then what repairs this highly oxidative radical? Could it be other carotenoids, isomers of carotenoids, or, as yet, undesignated phytochemicals?

As the free radical theory of disease (cancer) developed, the major participants were painted with a broad brush stroke-radical reactions were deleterious and anti-oxidants were beneficial. The difficulties in understanding the physiological responses by an anti/-pro-oxidant such as $\beta$-carotene are becoming more and more apparent from studies reflected here and influenced by factors such as target tissue concentrations, absorption by the target tissue, rate constants for radical reactions in the target tissue, localization and mobility with respect to hydrophobic and hydrophilic domains and turnover rates and cyclization [23] - all are factors that will affect $\beta$-carotene's action. We may add oxygen tension to this list. Under specific conditions, $\beta$-carotene may act as a pro-oxidant and fill a pro-carcinogenic role [24]. Perhaps $\beta$-carotene is a red-orange herring that has led hundreds of researchers down the proverbial rabbit hole, consuming millions in resources for the past 37 years in search of its anti-cancer properties. Perhaps the presence of $\beta$-carotene in those yellow/green vegetables merely cloaks the real anti-cancer agent. Nevertheless, the game remains afoot to explain how $\beta$-carotene, a molecule with superior antioxidant capacity under specific conditions and a singlet oxygen quencher, can act as a pro-carcinogen in UV-carcinogenesis and in lung cancer patients.

\section{References}

1. IARC (1998) Working group on the evaluation of cancer-preventive agents IARC handbooks of cancer prevention: Carotenoids, Lyon, IARC.

2. Foote CS, Denny RW (1968) Chemistry of singlet oxygen VII. Quenching by $\beta$-carotene. J Am Chem Soc 90: 6233-6235.

3. Truscott TG, Land EJ, Sykes A (1973) The in vitro photochemistry of biological molecules-III. Absorption spectra, lifetimes and rates of oxygen quenching of the triplet states of $\beta$-carotene, retinal, and related polyenes. Photochem Photobiol 17: 43-51.

4. Foote CS, Chang YC, Denny RW (1970) Chemistry of singlet oxygen X Carotenoid quenching parallels biological properties. J Am Chem Soc 92 5216-5218.

5. Mathews MM, Wilson T, Fujimori E, Krinsky NI (1974) Carotenoid chromophore length and protection against photosensitization. Photochem Photobiol 19: 217-222.

6. Krinsky NI, Deneke SM (1982) Interaction of oxygen and oxy-radicals with carotenoids. J Natl Cancer Institute 69: 205-210.

7. Polazza P, Moualla S, Krinsky NI (1992) Effects of $\beta$-carotene and $\alpha$-tocopherol on radical initiated peroxidation of microsomes. Free Radic Biol Med 13: 127-136.

8. Burton GW, Ingold KU (1984) Beta-carotene: An unusual type of lipid antioxidant. Science 224: 569-573.

9. Truscott TG (1996) $\beta$-carotene and disease: A suggested pro-oxidant and antioxidant mechanism and speculations concerning its role in cigarette smoking J Photochem Photobiol B Biol 35: 233-235.

10. Boehm F, Edge R, Truscott TG, Witt C (2016) A dramatic effect of oxygen on protection of human cells against $\mathrm{Y}$-radiation by lycopene. FEBS Letters 590 1086-1093.

11. Peto R, Doll R, Buckley JD, Sporn MB (1981) Can dietary beta-carotene materially reduce human cancer rates? Nature 290: 201-208.

12. Fairfield KM, Fletcher RH (2002) Vitamins for chronic disease prevention in adults. JAMA 287: 3116-3120.

13. Greenberg ER, Baron JA, Stukel TA, Stevens MM, Mandel JS, et al. (1990) A clinical trial of $\beta$-carotene to prevent basal-cell and squamous-cell cancer of the skin. N Engl J Med 323: 789-795.

14. The alpha-tocopherol, beta-carotene Cancer Prevention Study Group (1994) The effect of vitamin $E$ and beta-carotene on the incidence of lung cancer and other cancers in male smokers. N Engl J Med 330: 1029-1036.

15. Mathews-Roth MM (1982) Antitumor activity of $\beta$-carotene, canthaxanthin, and phytoene. Oncology 38: 33-37.

16. Mathews-Roth MM, Krinsky NI (1985) Carotenoid dose level and protection against UV-B-induced skin tumors. Photochem Photobiol 42: 33-38.

17. Black HS (1998) Radical interception by carotenoids and effects on UVcarcinogenesis. Nutr Cancer 31: 212-217.

18. Black HS, Okotie EG, Gerguis J (2000) Diet potentiates the UV-carcinogenic response to $\beta$-carotene. Nutr Cancer 37: 173-178.

19. Edge R, Land EJ, McGarvey D, Mulroy L, Truscott TG (1998) Relative one electron reduction potentials of carotenoid radical cations. J Am Chem Soc 120 4087- 4090 .

20. Boehm F, Edge R, Land EJ, McGarvey DJ, Truscott TG (1997) Carotenoids enhance vitamin E antioxidant efficiency. J Am Chem Soc 119: 621-622.

21. Black HS, Gerguis J (2003) Modulation of vitamins $E$ and $C$ fails to ameliorate $\beta$-carotene exacerbation of UV-carcinogenesis in mice. Nutr Cancer 45: 36-45.

22. Black HS (2010) Interaction of ascorbic acid and tocopherol on $\beta$-carotene modulated carcinogenesis. Hemoglobin 34: 284-290.

23. Pryor WA, Cornicelli JA, Devall LJ, Tait B, Trivedi BK, et al (1993) A rapid screening test to determine the antioxidant potencies of natural and synthetic antioxidants. J Org Chem 58: 3521-3532.

24. Black HS (2004) Reassessment of a free radical theory of cancer with emphasis on ultraviolet carcinogenesis. Integr Cancer Ther 3: 279-293. 